\title{
CEMUP
}

\section{Centro de Materiais da Universidade do Porto}

Uma experiência de uso partilhado de recursos avançados em ciência e tecnologia

\author{
C A R L S P. MOREIRA DE SÁ*
}

Resumo O CEMUP é uma infra-estrutura da Universidade do Porto que opera como um centro de meios tecnológicos comuns de apoio à investigação, na caracterização morfológica, microestrutural e microanalítica de materiais de natureza muito diversa. Neste artigo explicitam-se as motivações e sucessos que conduziram à sua constituição e progresso, identificam-se as suas facilidades e recursos experimentais, caracteriza-se a sua actividade e as perspectivas para o futuro. Procuro finalmente sintetizar e explicitar as lições recolhidas das dificuldades e sucessos de um percurso que tem já mais de duas décadas.
É hoje quase inquestionável a vantagem e a necessidade da partilha da utilização (e encargos) de equipamentos e infra-estruturas científicas de maior dimensão por grupos de investigadores com interesses comuns - eventualmente transversais a domínios de investigação ou áreas disciplinares.

Esta forma de proceder, que há décadas nos chega como exemplo de organização dos países mais avançados em ciência e tecnologia, apesar de mais ricos em recursos disponibilizados para investigação e desenvolvimento, teve contudo um lento progresso entre nós.

A pequena estória do CEMUP é certamente um dos exemplos da afirmação e vencimento desta ideia.

\section{Origem}

A constituição do CEMUP é fruto da iniciativa de um núcleo de investigadores dos Departamentos de Engenharia Metalúrgica e de Engenharia Mecânica da Faculdade de Engenharia do Porto FEUP e do Departamento de Física da Faculdade de Ciências do Porto a que se associaram outros investigadores das universidades do Minho e Aveiro, e que no final da década de 70 promoveram a criação de uma infra-estrutura, no âmbito da Universidade de recursos avançados de caracterização de materiais nomeadamente a microscopia electrónica - em condições de funcionamento regular e sustentado e acesso universal, em apoio da actividade dos investigadores na área dos materiais, que à data sentiam enormes carências neste domínio, mas que desde a primeira hora se pretendeu aberta a outras áreas científicas.

O apoio da Reitoria da Universidade do Porto a este projecto, e o suporte financeiro inicial da JNICT, da Fundação Gulbenkian e da INVOTAN permitiram a aquisição dos primeiros equipamentos, e a instalação em 1981 do primeiro laboratório de Microscopia Electrónica de Varrimento e Microanálise por Raios X. Esta iniciativa torna o CEMUP pioneiro na introdução no País de técnicas avançadas de caracterização microanalítica de materiais, na realização de actividades de formação nestas áreas, e na forma de disponibilizar o acesso aos seus laboratórios aos investigadores e às empresas, constituindo um verdadeiro centro de meios tecnológicos comuns, cujo financiamento depende de forma relevante dos investigadores e grupos que utilizam as instalações experimentais disponíveis nos seus laboratórios

O financiamento conseguido no quadro de programas de reforço da infra-estrutura tecnológica nacional - como o Projecto Educação Tecnológica financiado pelo Bird - e no âmbito de projectos de investigação permitiram que o CEMUP constituísse ao longo da década de noventa uma infra-estrutura relevante, na Universidade do Porto, e ao nível do País, no que se refere a técnicas avançadas de caracterização de materiais, por métodos de resolução espacial elevada, compreendendo instalações experimentais complementares integrando a microscopia óptica e análise quantitativa de imagem, a microscopia electrónica de varrimento (convencional e de elevada resolução) e microanálise por raios-X, e a análise de superfícies por espectroscopia de electrões.

Este resultado é fruto da acção prosseguida ao longo de mais de duas décadas, pela Comissão Instaladora, Comissão Directiva e investigadores e técnicos envolvidos na actividade do CEMUP, do interesse e apoio continuado da Reitoria da Universidade do Porto e dos muitos investigadores com interesse na sua actividade. 

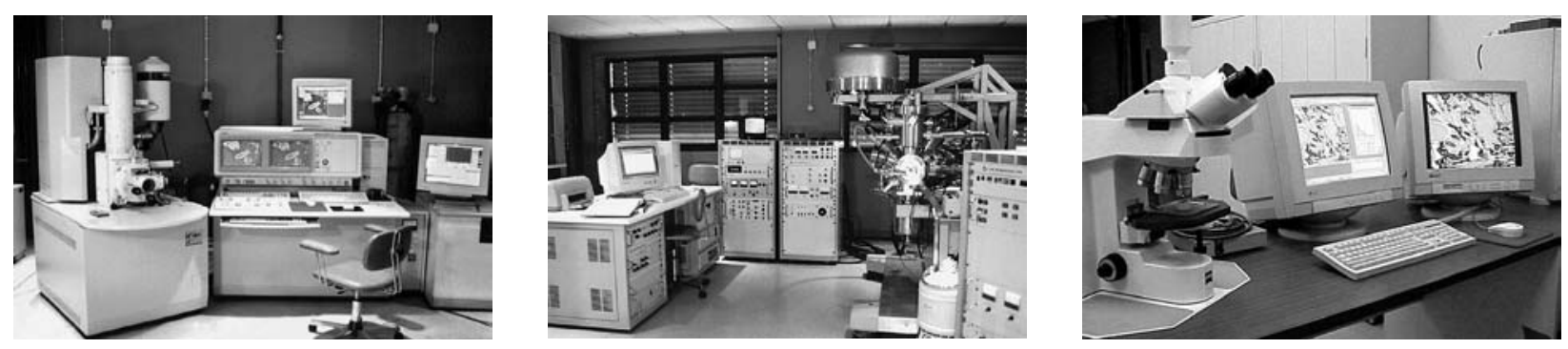

Figura 1 Laboratórios do CEMUP - microscopia electrónica de varrimento e microanálise por raios X, de análise de superfícies e de metalografia quantitativa

\section{Objectivos, actividade e modo de funcionamento}

O CEMUP foi constituído com o propósito de apoiar as actividades de investigação e desenvolvimento e de formação científica e técnica de quadros superiores na área dos materiais, de qualquer natureza, servindo os diferentes departamentos e centros de investigação da Universidade do Porto, de outras universidades, instituições públicas e privadas e empresas industriais.

Na prossecução deste objectivo, e dispondo de recursos experimentais para a caracterização de materiais com elevada resolução espacial, a actividade do CEMUP está centrada no apoio às actividades de investigação e desenvolvimento e na prestação de serviços à industria e laboratórios envolvendo o estudo e caracterização morfológica, microestrutural e microanalítica de materiais, e na realização de acções de formação científica e técnica de quadros de nível superior.
O desenvolvimento da sua actividade e modo de funcionamento tem tido como princípios orientadores:

- Funcionamento como uma estrutura aberta com actividade dirigida para o exterior e centrada no interesse dos investigadores que utilizam a infra-estrutura, assegurando acesso universal e apoiado (serviço) às instalações experimentais;

- Actividade diversificada de prestação de serviços aos investigadores, a unidades de interface da universidade e ao exterior: a laboratórios, institutos tecnológicos e empresas;

- Actividade diversificada de formação: empenhamento na formação inicial e avançada de investigadores e estudantes pós-graduados e dos cursos regulares da U.P., realização regular de cursos de formação e acções de demonstração científico-técnica, máxima disponibilidade para acções de colaboração;
- Adopção do princípio da partilha de recursos - partilha de custos, assegurando uma capacidade mínima de auto-financiamento que permita uma resposta expedita às necessidades de manutenção/reparação dos equipamentos;

Estes princípios, presentes desde a entrada em funcionamento das primeiras instalações experimentais, enformam a sua organização e regulamento de prestação de serviços.

Com limitações que certamente se podem apontar à sua actividade e funcionamento, o CEMUP tem contribuído de forma significativa para o desenvolvimento da actividade de investigadores provenientes de uma grande diversidade de áreas disciplinares: física, química, engenharias metalúrgica e de materiais, química, mecânica e civil, biologia e medicina, geologia e arqueologia, da Universidade do Porto e de outras universidades portuguesas, que se traduz no acesso aos seu laboratórios por cerca

Figura 2 Imagem de microscopia electrónica de varrimento de um material compósito (matriz polimérica + fibra de vidro) e espectro de emissão de raios $\mathrm{X}(\mathrm{EDS})$ da uma amostra metálica
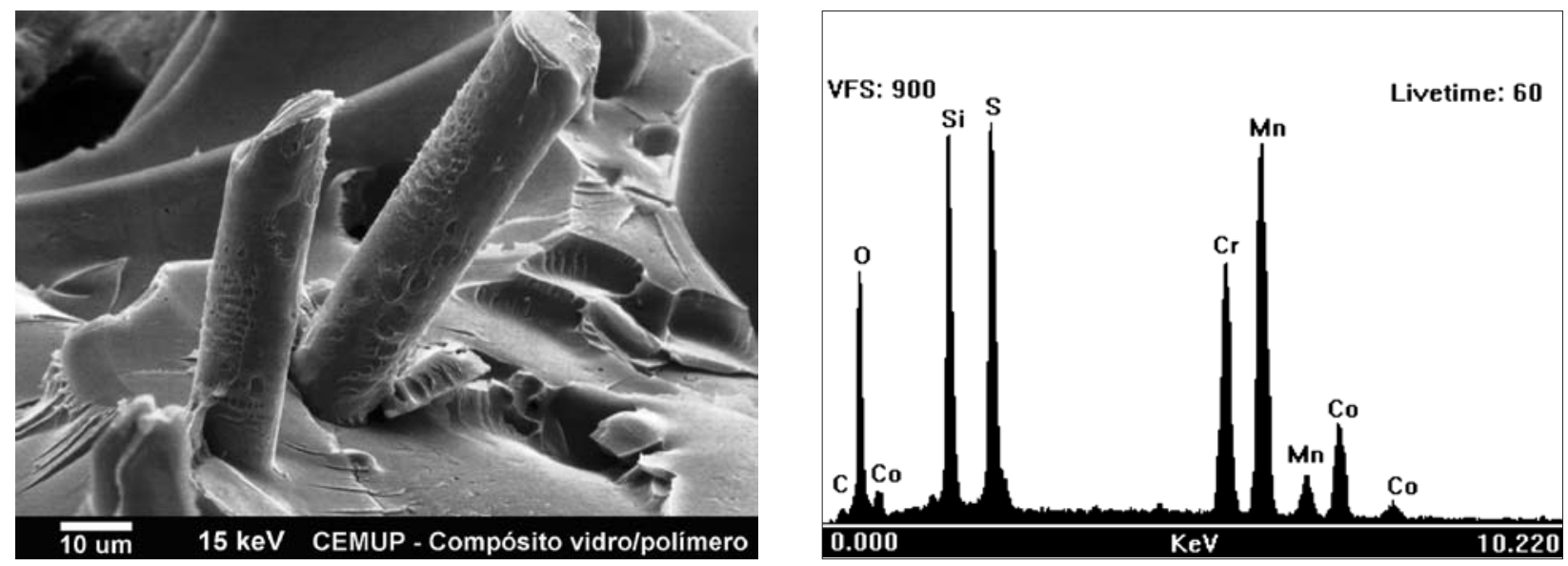
de uma centena de investigadores/ano, em média nos últimos anos, dos quais mais de $25 \%$ são exteriores à U.P..

As actividades de formação exprimem-se na realização regular de acções de formação, desde 1987, nas áreas das técnicas disponíveis nos seus laboratórios - microscopia electrónica, análise de superfícies e análise de imagem para caracterização da microestrutura de materiais - que envolveram mais de 450 investigadores e técnicos ao longo de mais de uma década, e pela colaboração em cursos de mestrado e em outras activi- dades de formação pós-graduada e curriculares dos cursos da U.P.

\section{Instalações experimentais. Laboratórios}

Os laboratórios do CEMUP, apresentados na Figura 1, constituem um conjunto coerente de instalações experimentais complementares e compreendem:

- O Laboratório de Microscopia Electrónica de Varrimento e Microanálise por Raios X (SEM/EDS convencional e FESEM/EDS) com vocação para a caracte- rização morfológica, microestrutural e microanalítica de materiais muito diversos, como exemplifica a Figura 2 ;

- O Laboratório de Análise de Superfícies por espectroscopia de electrões (XPS/AES) vocacionado para o estudo e caracterização química de superfícies e interfaces - no estado primário ou modificadas por acção experimental, exemplificado na Figura 3;

- O Laboratório de Metalografia Quantitativa (microscopia óptica e análise quantitativa de imagem) vocacionado

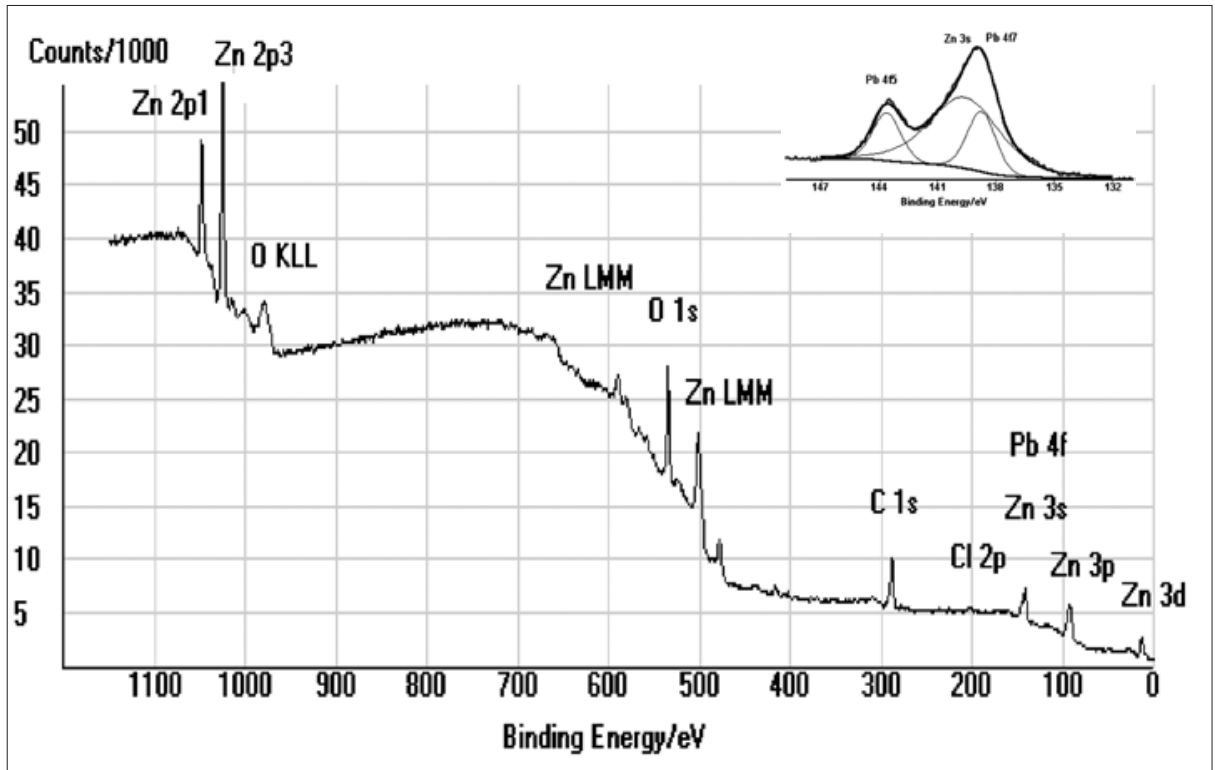

Figura 3 Espectro XPS de uma amostra metálica sujeita a tratamento da superfície

para o exame e caracterização morfológica/microestrutural de amostras com preparação metalográfica (secções planas), como mostra a Figura 4;

- Meios complementares de preparação de amostras e materiais

Existem também um secretariado, uma pequena biblioteca, sala de cursos e gabinetes para investigadores, instalados em edifício próprio.

\section{Perspectivas para o futuro}

A importância do desenvolvimento da investigação na área dos materiais, motivou as unidades de investigação da U.P. nesta área no propósito de assegurar a actualização tecnológica dos labo- ratórios existentes na U.P., com introdução de novas valências nos métodos já disponíveis, e instalação de novos equipamentos experimentais para outras técnicas avançadas de caracterização (não disponíveis ou de difícil acesso na comunidade académica a nível regional ou nacional), que são indispensáveis ao prosseguimento da investigação na área dos materiais e em áreas com interesses afins.

A utilização partilhada de recursos constitui uma forma eficaz de um grande número de investigadores de diferentes grupos e áreas de investigação aceder a equipamentos científicos e tecnológicos avançados, quer por motivo do seu custo de aquisição ou de operação/manutenção, quer pela necessidade de constituir uma massa crítica que permita o concurso de pessoal técnico especializado e assegure a utilização continuada e apoiada dos equipamentos em condições de operacionalidade e eficácia.

O reconhecimento deste princípio, já consubstanciado no CEMUP, e da relevância dos recursos, actividade e experiência desta infra-estrutura, conduziu à constituição de um consórcio de uma dezena de unidades de investigação, associando o CEMUP como parceiro estratégico, que deverá permitir assegurar através da execução de um projecto submetido ao Programa de Re-equipamento Científico da FCT, a actualização tecnológica das instalações já disponíveis de microscopia electrónica de varri- 
Figura 4 Análise de imagem da microestrutura de um ferro fundido, obtida por microscopia óptica

mento - com introdução de novas valências de CrioSEM, ESEM e EBSD - e a introdução de novas tecnologias de microscopia de varrimento de sonda SPMAFM/STM.

\section{As lições de um percurso}

A actividade regular do CEMUP desde há mais de duas décadas, com a utilização continuada dos seus laboratórios por um número elevado de investigadores de uma diversidade de instituições e grupos de investigação a nível local e nacional, e o interesse no prosseguimento e alargamento da sua actividade, comprovados pela sua associação a um consórcio de Unidades de Investigação da U. P. que protagoniza um projecto para o seu re-equipamento, atestam a relevância da sua actividade para o desenvolvimento da investigação na área dos materiais.

A origem e o longo período de actividade do CEMUP, oferecem uma experiência de que é possível extrair contributos para a discussão e definição dos princípios orientadores e condições de funcionamento de centros de recursos científicos e tecnológicos de uso comum.

Do que aprendi ao longo desta experiência que tive oportunidade de contribuir para colocar em prática, considero de realçar as seguintes orientações fundamentais, que apenas enumero sem discussão mais detalhada:

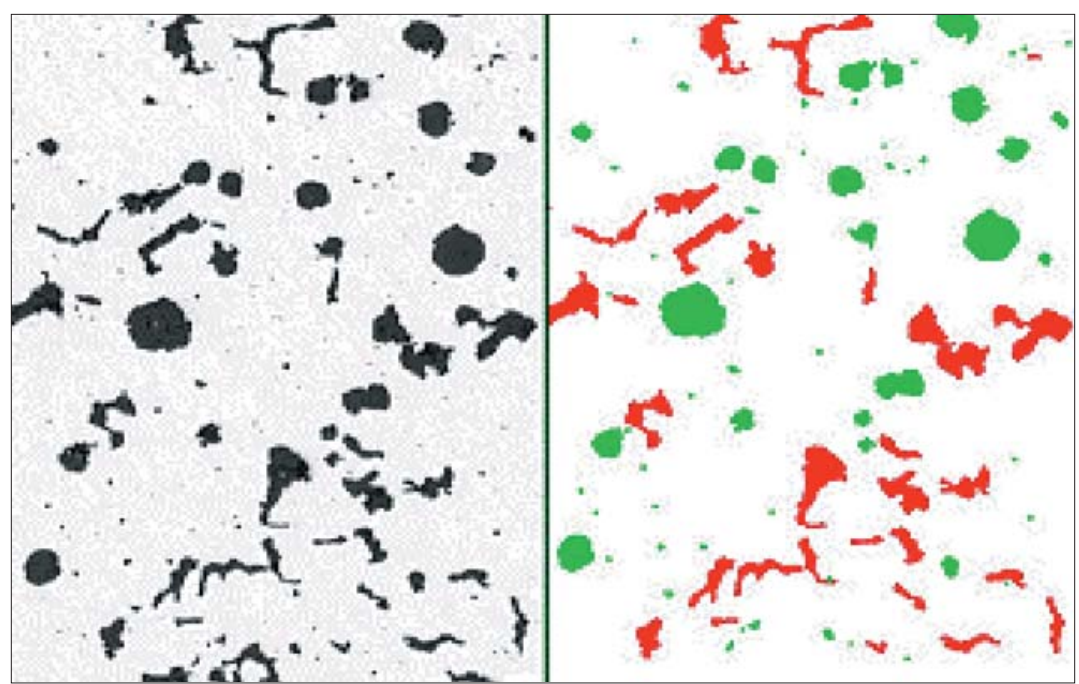

I. A afirmação do interesse comum de partilha de recursos por um conjunto alargado de investigadores/unidades de investigação, com a fixação de objectivos e de um quadro institucional bem definido;

II. A constituição de uma infra-estrutura com uma massa crítica mínima de recursos experimentais e competências, integrando recursos humanos com formação adequada, motivação e horizonte temporal de actividade alargado;

III. A organização e funcionamento como estrutura aberta com actividade dirigida para o exterior e centrada no interesse dos investigadores que utilizam a infra-estrutura: consubstanciada em condições de acesso universal e apoiado (serviço) e multidisciplinar aos meios experimentais;

IV. A actividade diversificada integrando três componentes fundamentais:

a. o apoio às actividades de investigação e desenvolvimento dos investigadores - utilização apoiada das instalações experimentais e prestação de serviços a unidades de interface;

b. a prestação de serviços ao exterior: a laboratórios, institutos tecnológicos e empresas

c. o empenhamento no desenvolvimento de actividades de formação inicial e avançada de investigadores e estudantes pós-graduados e acções de demonstração;
V. A adopção do princípio da partilha de recursos - partilha de custos, com vista a assegurar uma capacidade mínima de auto-financiamento que permita uma resposta expedita às necessidades de manutenção/reparação dos equipamentos;

VI. A supervisão pelos grupos de investigadores com especial interesse na infra-estrutura: na definição das normas gerais de organização e funcionamento, planos de actividade e dos objectivos de desenvolvimento de médio prazo.

Tomando por referência estes princípios orientadores, o sucesso relativo do projecto do CEMUP, resulta também, manifestamente, de algumas características específicas. Merecem especial realce a adequação dos recursos experimentais ao interesse de um sector relevante de investigadores e áreas de investigação, a continuidade e regularidade da actividade dos laboratórios e da sua utilização apoiada por pessoal tecnicamente competente, a complementaridade dos equipamentos e laboratórios e a rentabilização dos equipamentos resultante da sua utilização comum e da partilha dos encargos de funcionamento.

Por último, mas com especial importância e actualidade, o facto de a partilha de recursos comuns constituir uma plataforma e estímulo de cooperação interdisciplinar/multidisciplinar entre investigadores. 